\title{
An interesting case of complicated aortobifemoral graft: duodenal migration and colonic perforation
}

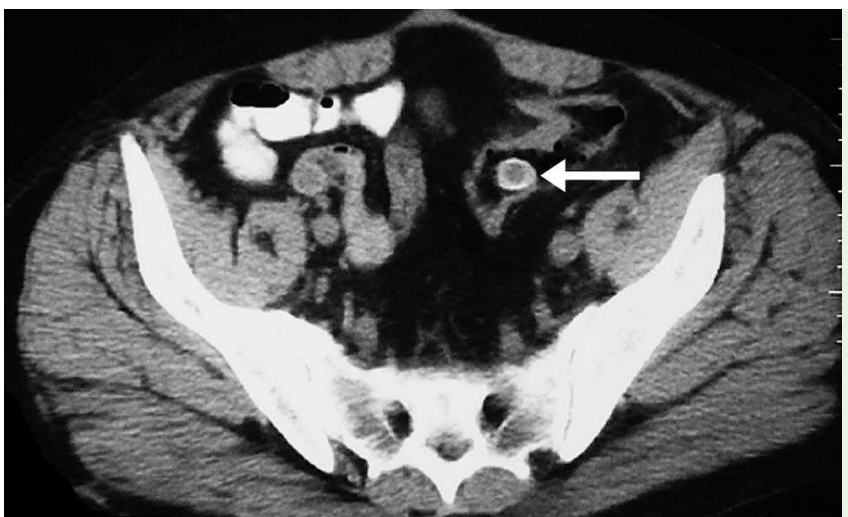

Fig. 1 CT of abdomen The limb of the aortobifemoral graft (arrow) is within the lumen of sigmoid colon.

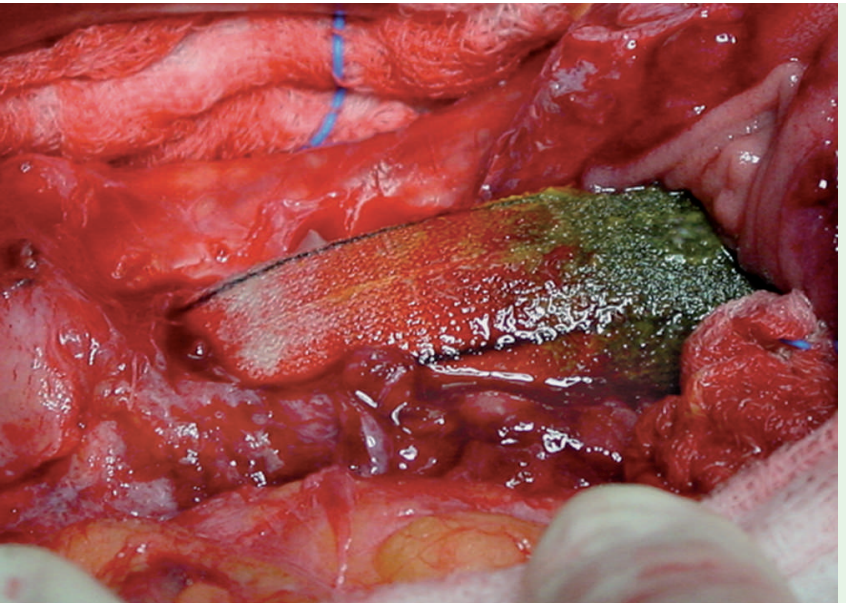

Fig. 3 Surgical view of the intraduodenal part of the aortobifemoral graft, which was infected and eroded.

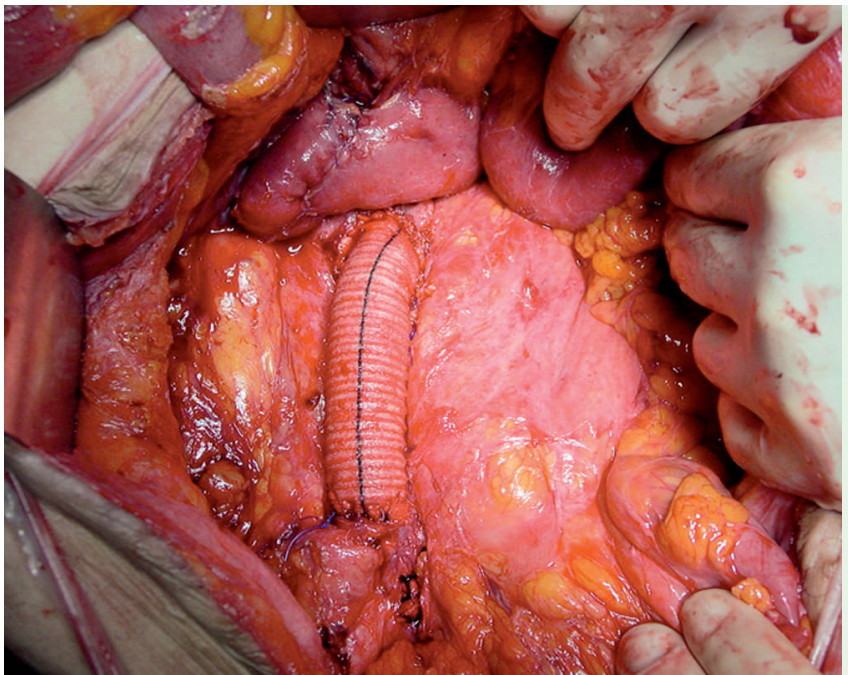

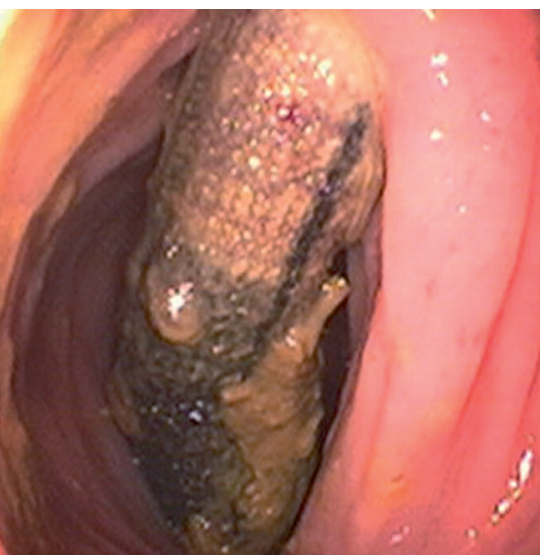

Fig. 2 Colonoscopic view of the aortobifemoral graft inside the sigmoid colon.

Here we present a case of complicated aortobifemoral graft. To the best of our knowledge it is the only case reported in the literature in which duodenal migration and colonic perforation were observed together and a colonoscopic view was obtained.

A 55-year-old man was admitted to our clinic with left groin pain and purulent discharge. He had undergone aortobifemoral trouser graft surgery 3 months ago, for severe obstructive atherosclerosis. The laboratory work-up revealed leukocytosis and an elevated erythrocyte sedimentation rate. Physical examination revealed a palpable mass in the left inguinal region, from which a purulent exudate oozed on applying pressure. Computed tomography (CT) showed that the main body of the graft was in the duodenal lumen and the left limb of the graft had perforated the adjacent sigmoid colon toward the skin ( Fig. 1). There was an abscess beneath the skin in this region. Flexible sigmoidoscopy demonstrated a white tubular object lying across the lumen of the sigmoid colon ( $\bullet$ Fig. 2). It was partially coated with feces. The mucosa around the object appeared normal after gentle washing and no blood was observed. The patient underwent surgery, and the intraduodenal part of the graft, which was infected and eroded ( $\odot$ Fig. 3 ), was resected and a new graft was interposed ( $\bullet$ Fig. 4 ). The left limb of the graft was extracted from the sigmoid colon and the entrance and exit holes were repaired by primary 
suture. A left superficial femoral vein graft was implanted in place of the extracted limb.

Aortoenteric fistulas are not rare complications of aortofemoral graft surgery. Disruption of the suture lines may cause a pseudoaneurysm, which erodes the adjacent bowel wall with time [1]. Infection of the suture lines and intraoperative technical mistakes, which result in injury to bowel segments, may have a role in the migration of the graft from the retroperitoneum into duodenum or adjacent colon segments [2]. The duodenum is the most frequently involved segment, whereas the colon is the least frequently affected part [3]. CT is important for prompt diagnosis of complications of aortofemoral grafts. Endoscopic examination may be necessary to confirm the diagnosis as in our case, but it is not required most of the time. Endoscopy should be performed gently with as little air as possible to avoid perforation. Timely surgical intervention is essential in the treatment.

Endoscopy_UCTN_Code_CCL_1AD_2AH

Endoscopy_UCTN_Code_CCL_1AD_2AJ
M. Ibis ${ }^{1}$, I. K. Onal ${ }^{1}$, C. L. Birincioglu², G. Nessar ${ }^{3}$, M. Kurt ${ }^{1}$, B. Celep ${ }^{3}$, M. A. T. Ozkan $^{2}$, A. Tas ${ }^{1}$, A. Sayilir ${ }^{1}$, N. Sasmaz ${ }^{1}$

1 Department of Gastroenterology, Turkiye Yuksek Ihtisas Teaching and Research Hospital, Ankara, Turkey

2 Department of Cardiovascular Surgery, Turkiye Yuksek Ihtisas Teaching and Research Hospital, Ankara, Turkey

3 Department of Gastrointestinal Surgery, Turkiye Yuksek Ihtisas Teaching and Research Hospital, Ankara, Turkey

\section{References}

1 Tsunekawa $T$, Ogino $H$, Minatoya $K$ et al. Masked prosthetic graft to sigmoid colon fistula diagnosed by 18-fluorodeoxyglucose positron emission tomography. Eur J Vasc Endovasc Surg 2007; 33: 187-189

2 Marrocco-Trischitta MM, Marone EM, Kahlberg $A$ et al. latrogenic sigmoid perforation by aortobifemoral left graft limb. Surgery 2008; 144: 103 - 104

3 Bunt TJ. Synthetic vascular graft infections, II. Graft-enteric erosions and graft-enteric fistulas. Surgery 1983; 94: 1-9
Bibliography

DOI $10.1055 / \mathrm{s}-0029-1214626$

Endoscopy 2009; 41: E184-E185

(c) Georg Thieme Verlag KG Stuttgart · New York . ISSN 0013-726X

Corresponding author

M. Kurt, MD

Department of Gastroenterology

Turkiye Yuksek Ihtisas Teaching and Research Hospital

Kızılay Sk. No. 2

06100 Sihhiye

Ankara

Turkey

Fax: +90-312-3124120

dr.mevlutkurt@gmail.com 